\title{
Short- and long-term effects of asphyxia on juvenile play
}

\author{
KAREN L. MIKLOSOVIC and JAAK PANKSEPP \\ Bowling Green State University, Bowling Green, Ohio
}

\begin{abstract}
The possibility that asphyxia may influence social processes was evaluated in two experiments. In the first, juvenile rats were asphyxiated and their play behavior (as measured by pins and dorsal contacts) was measured immediately and $30 \mathrm{~min}$ following recovery. Although the asphyxiated rats' play was substantially reduced immediately following recovery, they exhibited no play changes 30 min later. The immediate play deficit was not modified by opioid blockade with $1 \mathrm{mg} / \mathrm{kg}$ of naloxone. In the second experiment, repeated asphyxiation during the neonatal period was found to have no effects on the subsequent development of juvenile play. These experiments provide no evidence for a role of asphyxia and opioids in the control of social development of mammals.
\end{abstract}

Neonatal asphyxia can severely impair the cognitive and behavioral abilities of both humans and animals (Gottfried, 1973; Moshe \& Albala, 1985), leading to mental retardation, motor difficulties (Kreusser \& Volpe, 1984), and pain perception deficits (Sandman et al., 1979). Recent work indicates that acute asphyxia also releases $\beta$ endorphins (Wardlaw, Stark, Daniel, \& Frantz, 1981), possibly to counteract the physiological changes caused by stressful circumstances. Asphyxia-induced physiological and behavioral changes may be mediated, in part, by such opioid secretion, for some short-term physiological effects of asphyxia have been reversed by opioid receptor antagonists, such as naloxone (Chernick \& Craig, 1982).

To our knowledge, there has been no research to date concerning the consequences of asphyxia on the elaboration of social behaviors. Since perinatal complications are a potentially important vector in the development of early childhood autism (Coleman, 1976), and since that syndrome is characterized by major deficits in social relationships, we deemed it important to determine whether asphyxia could reduce social behavior. Play behavior was specifically selected for study because it is known to be modulated by opioids-low doses of morphine increase and high doses reduce play (Panksepp, Herman, Vilberg, Bishop, \& DeEskinazi, 1980; Panksepp, Jalowiec, DeEskinazi, \& Bishop, 1985; Panksepp, Siviy, \& Normansell, 1984). Furthermore, the fact that early childhood autism seems to reflect a general developmental delay (Walker, 1976) that is potentially mediated by excess opioid activity during critical periods of development (Panksepp \& Sahley, 1987) indicates the need for more work on the relationship between asphyxia, opioids, and social responsivity.

The present experiments were designed to evaluate the acute effects of asphyxia on play behavior of juvenile rats,

Address correspondence to Jaak Panksepp, Department of Psychology, Bowling Green State University, Bowling, Green, OH 43403. and the long-term consequences of neonatal asphyxia on the subsequent development of juvenile play. From the perspective of autism, it was anticipated that these manipulations would reduce play under both conditions, and, if these effects are mediated by excess opioid activity, that they would be reversed with naloxone. It should be noted that this last prediction is problematic, in that past work has found naloxone to typically reduce social play (Panksepp et al., 1980; Panksepp et al., 1984; Panksepp et al., 1985). It should also be noted, however, that under the appropriate conditions, naloxone can increase play solicitation (Panksepp et al., 1984). In any event, after consideration of the above literature, we deemed it worthwhile to systematically analyze the relationships between asphyxia and basic social competence.

\section{METHOD}

\section{Subjects}

Subjects were Long-Evans rats $(n=38)$, family housed in metal suspended cages until weaning at 21 days of age. Pups were then individually housed, and remained on a $12 \mathrm{~h}$ light/dark schedule with free access to food and water. For testing purposes, animals were matched for weight and were assigned to same-sex play partners. Differences in natural coat coloration allowed easy scoring of individual animals.

\section{Apparatus}

The play apparatus has been described before (Panksepp et al., 1985). Briefly, it consisted of a Plexiglas test box situated within a soundattenuated chamber with a Plexiglas observation window. The apparatus was illuminated with a 25-W red light bulb. An activity counter was connected to the test box to monitor activity during rough-and-tumble play. Pins, pin durations, and dorsal contacts were also measured, as previously described (Panksepp et al., 1985).

\section{Procedure}

Play partners were placed under a bell jar (volume $=4,250 \mathrm{ml}$ ) with a carbon dioxide-filled balloon (approximate volume $=3,400 \mathrm{ml}$ ) attached to the top. The contents of the balloon were emptied into the jar by loosening a bulldog clamp. Subjects remained in the jar for $1 \mathrm{~min}$ afterward, which was sufficient to just render the animals unconscious. Subjects were then removed from the jar. After a 1-min latency period, to allow just enough time for recovery of motor arousal, they were placed in the test box for a play session lasting $5 \mathrm{~min}$. After a 30-min period dur- 
ing which the subjects remained alone in their home cages, the pairs were tested again.

Experiment 1. The first experiment utilized juvenile rats at two ages. Young juvenile rats were habituated to play sessions at 22 days of age and testing began at 25 days of age. Older juveniles were habituated to play sessions at 37 days of age and testing began at $\mathbf{4 0}$ days of age. The subjects were tested in a counterbalanced manner following carbon dioxide asphyxia or an identical time under the bell jar with no gas administered. Subjects were also tested again, as above, $15 \mathrm{~min}$ following treatment with naloxone $(1 \mathrm{mg} / \mathrm{kg}$, ip) or distilled water vehicle.

Experiment 2. Experiment 2 utilized neonates chronically subjected to asphyxia. Subjects were divided into experimental and control groups. Neonates were asphyxiated once daily with carbon dioxide (using the same procedure as above) from ages 2 through 12 days. One minute after each asphyxiation trial, pups were reunited with their mothers. At 22 days of age, they were habituated to play, and at 25 days of age, they were tested in the play chamber for four consecutive daily sessions.

\section{RESULTS}

\section{Experiment 1}

Immediately following carbon dioxide asphyxia, play was reduced by about one third in both the young and older rats. As summarized in Figure 1, carbon dioxide reduced the number of pins $[t(11)=4.54, p<.01]$ and play solicitations $[t(11)=5.13, p<.001]$ at the first postasphyxia test period, but play was back to normal 30 min later.

Naloxone reduced the number of pins for the control group $[t(11)=3.82, p<.01]$, but not for the carbon dioxide-treated animals (see Figure 2). There was no effect of naloxone on play solicitations for either the control or the experimental group.

Additional tests using older juveniles revealed an immediate reduction, following carbon dioxide, in the number of pins [from 6.2 to 2.1 pins per $5 \mathrm{~min}, t(7)=3.27$, $p<.02$ ] and play solicitations [from 13.2 to 3.7 per $5 \min , t(7)=3.05, p<.02$ ]. Again, no differences were evident at the 30 -min interval.

\section{Experiment 2}

The average number of pins for controls for the 4 successive days of testing were $24.6,26.2,26.4$, and 26.0
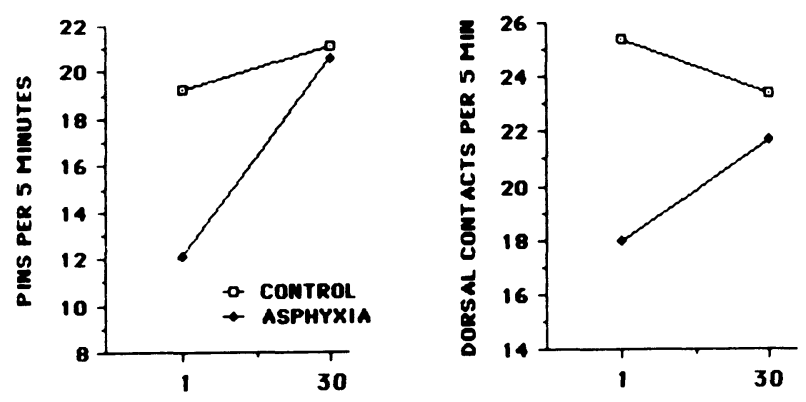

INTERVAL BETWEEN ASPHYXIA AND TESTING (Mins)

Figure 1. The number of pins and dorsal contacts as a function of the interval between asphyxia and testing in control and asphyxiated groups.
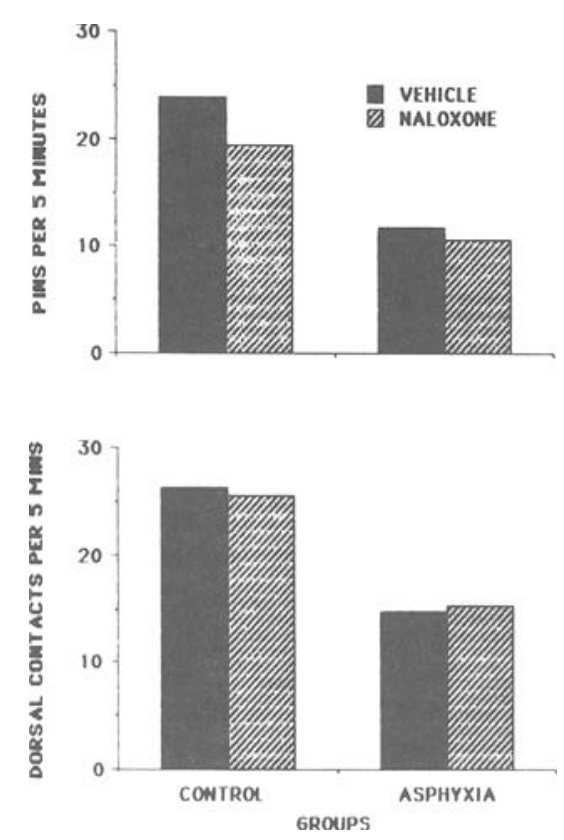

Figure 2. The number of pins and dorsal contacts as a function of drug condition in control and asphyxiated groups at the immediate test interval.

pins per $5 \mathrm{~min}$. For animals asphyxiated neonatally, the scores were $24.6,24.6,21.4$, and 18.9 pins per $5 \mathrm{~min}$. There was no carbon dioxide effect across days for the number of pins $[F(1,16)=0.82]$. Also, the scores for play solicitations between groups were essentially identical $[F(1,16)=0.13]$. There were no day effects for either measure, nor was any day $\times$ treatment interaction apparent.

\section{DISCUSSION}

This study clearly indicates that asphyxia powerfully reduces play immediately after induction (as measured by pins and dorsal contacts), but the effect disappears within $30 \mathrm{~min}$. Although previous work has indicated that some of the physiological effects of asphyxia are mediated by opioid secretion (Chernick \& Craig, 1982), there was no evidence of such an influence in the present study. Naloxone was not able to reverse the short-term effects of asphyxia. Still, it is noteworthy that although naloxone produced the anticipated reduction of play in control animals (see Panksepp et al., 1984), this effect was not apparent in the asphyxiated rats. This may suggest that opioid-mediated control of play is diminished in asphyxiated rats, but such an interpretation is compromised by the much lower baseline levels of play in asphyxiated rats. Naloxone did not affect play solicitations in either control or asphyxiated rats, suggesting that motivation for play was not reduced by opioid blockade. In general, these results provide no support for the idea that asphyxia has long-term effects on brain mechanisms that elaborate social behaviors.

In order to determine whether asphyxia might have more permanent effects on social development, animals were treated with carbon dioxide during early infancy, and play behavior was tested during the juvenile period. No long-term effect of asphyxia was observed. In sum, the present work provides no support for the conclusion that asphyxia can provoke neurophysiological changes that compromise social development. Although more intensive challenges on subjects at different ages need 
to be done before any final conclusion can be reached on this issue, the present work does not support the idea that asphyxia may be an important dimension in the development of social changes such as those that characterize autism.

\section{REFERENCES}

Chernick, V., \& Craig, R. J. (1982). Naloxone reverses neonatal depression caused by fetal asphyxia. Science, 216, 1252-1253.

Coleman, M. (1976). The autistic syndromes. Amsterdam: North Holland.

GoTTFRIED, A. W. (1973). Intellectual consequences of perinatal anoxia. Psychological Bulletin, 80, 231-242.

KreUSSER, K. L., \& VolPE, J. J. (1984). The neurological outcome of perinatal asphyxia. In C. R. Almli \& S. Finger (Eds.), Early brain damage: Vol. 1. Research orientations and clinical observations (pp. 151-168). Orlando, FL: Academic Press.

Moshe, S. L., \& Albala, B. J. (1985). Perinatal hypoxia and subsequent development of seizures. Physiology \& Behavior, 35, 819-823.

Panksepp, J., Herman, B. H., Vilberg, T., Bishop, P., \& DeEskinazi, F. G. (1980). Endogenous opioids and social behavior. Neuroscience \& Biobehavioral Reviews, 4, 473-487.

Panksepp, J., Jalowiec, J., DeEskinazi, F. G., \& Bishop, P. (1985).
Opiates and play dominance in juvenile rats. Behavioral Neuroscience, 99, 441-453.

Panksepp, J., \& SAhley, T. L. (1987). Possible brain opioid involvement in disrupted social intent and language development of autism In E. Schopler \& G. Mesibov (Eds.), Neurobiological issues in autism (pp. 357-372). New York: Plenum Press.

Panksepp, J., Siviy, S., \& Normansell, L. (1984). The psychobiology of play: Theoretical and methodological perspectives. Neuroscience \& Biobehavioral Reviews, 8, 465-492.

Sandman, C. A., McGisera, R. F., Berka, C., Walker, J. M., Coy, D. H., \& KASTIN, A. J. (1979). Neonatal administration of $\beta$-endorphin produces 'chronic' insensitivity to thermal stimulus. Life Sciences, $25,1755-1760$.

WALKER, H. A. (1976). Incidence of minor physical anomalies in autistic patients. In M. Coleman (Ed.), The autistic syndromes (pp. 95-115). Amsterdam: North Holland.

Wardlaw, S. L., Stark, R. I., Daniel, S., \& Frantz, A. G. (1981). Effects of hypoxia on $\beta$-endorphin and $\beta$-lipotrophin release in fetal, newborn and maternal sheep. Endocrinology, 108, 1710-1715.

(Manuscript received for publication December 12, 1986.) 